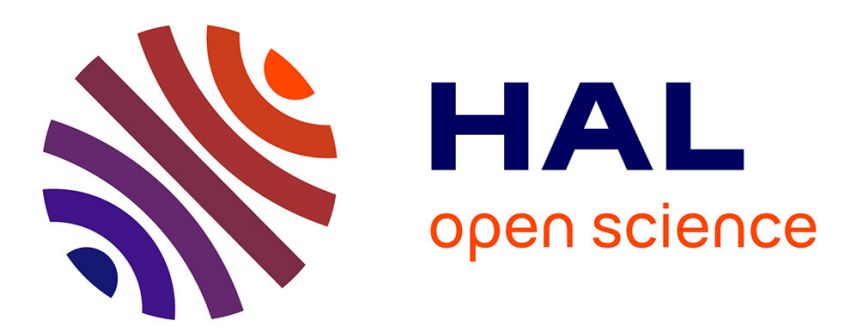

\title{
Determination of porosity change from shrinkage curves during drying of food material
}

J. Madiouli, J. Sghaier, Didier Lecomte, H. Sammouda

\section{To cite this version:}

J. Madiouli, J. Sghaier, Didier Lecomte, H. Sammouda. Determination of porosity change from shrinkage curves during drying of food material. Food and Bioproducts Processing, 2012, 90 (C1), pp.43-51. 10.1016/j.fbp.2010.12.002 . hal-01688419

\section{HAL Id: hal-01688419 https://hal.science/hal-01688419}

Submitted on 18 Nov 2018

HAL is a multi-disciplinary open access archive for the deposit and dissemination of scientific research documents, whether they are published or not. The documents may come from teaching and research institutions in France or abroad, or from public or private research centers.
L'archive ouverte pluridisciplinaire HAL, est destinée au dépôt et à la diffusion de documents scientifiques de niveau recherche, publiés ou non, émanant des établissements d'enseignement et de recherche français ou étrangers, des laboratoires publics ou privés. 


\title{
Determination of porosity change from shrinkage curves during drying of food material
}

\author{
J. Madiouli ${ }^{a, *}$, J. Sghaier $^{a}$, D. Lecomte ${ }^{b}$, H. Sammouda ${ }^{a}$ \\ ${ }^{a}$ LETTM, Faculté des sciences de Tunis, 1060 Tunis, Tunisia \\ b Université de Toulouse, Mines Albi, F 81013 Albi, France
}

\begin{abstract}
A B S T R A C T
Based on a very simple model of mass conservation, three experimental properties (solid density, liquid density and initial bulk density) and the simultaneous acquisition of the reduced moisture content and the volume shrinkage during drying, a simple method is proposed to calculate the bulk porosity of a material during drying. This model allows a graphical interpretation to visualize the porosity change by comparing the experimental shrinkage curve with an ideal shrinkage curve. In the present work, several examples were taken from the literature to illustrate the application of this method to foodstuffs (apple, banana, carrot, garlic, pear, potato and sweet potato) with two different processes (convective drying, freeze-drying) and different drying conditions. Porosity calculations including error estimations showed a good agreement with experimental values reported in the literature.
\end{abstract}

Keywords: Porosity; Model; Foodstuffs; Shrinkage; Collapse

\section{Introduction}

Drying is used to store food safely by reducing the moisture content and decreasing the microbiological activity. The drying process usually causes volume and surface change of fruit and vegetables due to moisture evaporation. Changes in the physical properties (density, porosity, etc.) can be observed and influence the product quality and consumer's opinion. Among these properties, porosity, defined as the ratio of the pore volume to the apparent volume of the medium, is strongly dependent on the moisture content and the drying conditions.

Important work on the porosity change during the drying of foodstuffs is reported in the literature (Lozano et al., 1980, 1983; Madamba et al., 1994; Ratti, 1994; Zogzas et al., 1994; Krokida and Maroulis, 1997; Azzouz et al., 2002; Talla et al., 2004; Mayor and Sereno, 2004). During drying, the shrinkage is known as ideal or perfect when the volume reduction of the solid matrix is strictly proportional to the mass loss. On the other hand, the pores appear if the volume reduction is smaller than the theoretical reduction due to liquid water removal. The variation of the porosity can result from the change of the apparent volume or the change of the pore volume by two phenomena: shrinkage and/or collapse (Rahman, 2003; Khalloufi et al., 2009, 2010). The collapse causes the decrease of the pore initial volume, although the non ideal shrinkage tends to increase it. The pore volume can be determined by appropriate measurement devices (porosimetry) involving the intrusion of a non-wetting fluid (mercury, nitrogen) in the pore network. It can also be determined indirectly by measuring the bulk density and the solid density. Apparent volume measurement can be achieved without contact (chromatography, laser and stereovision) or with contact from the geometric dimension measurement (Madiouli et al., 2007). The experimental measurement of porosity requires either the interruption of the experiment (this creating a bias in the results), or the use of several samples dried under the same conditions of drying.

In the literature, the shrinkage or the change of apparent volume during drying is determined by fundamental models (Vacarezza, 1975; Suzuki et al., 1976; Lozano et al., 1983; Perez and Calvelo, 1984; Rahman et al., 1996; Katekawa and Silva, 2004) and empirical correlations (Lozano et al., 1980; Ratti, 1994; Zogzas et al., 1994; Azzouz et al., 1998; Mayor and Sereno, 2004). The latter can only be used for limited prod-

\footnotetext{
* Corresponding author. Tel.: +216 22729305.

E-mail addresses: jamel_mad@yahoo.fr (J. Madiouli), didier.lecomte@mines-albi.fr (D. Lecomte).
} 


\begin{tabular}{|ll|}
\hline \multicolumn{2}{|l|}{ Nomenclature } \\
$\mathrm{m}$ & mass $(\mathrm{kg})$ \\
$\mathrm{V}$ & bulk (or apparent) volume $\left(\mathrm{m}^{3}\right)$ \\
$\mathrm{V}_{\mathrm{p}}$ & particle volume $\left(\mathrm{m}^{3}\right)$ \\
$\mathrm{X}$ & moisture content $(\mathrm{kg}$ of water $/ \mathrm{kg}$ of dry solid) \\
& \\
Greek letters \\
$\varepsilon$ & porosity \\
$\rho$ & bulk density $\left(\mathrm{kg} / \mathrm{m}^{3}\right)$ \\
$\rho_{\mathrm{L}}$ & density of solvent $\left(\mathrm{kg} / \mathrm{m}^{3}\right)$ \\
$\rho_{\mathrm{S}}$ & density of solid $\left(\mathrm{kg} / \mathrm{m}^{3}\right)$ \\
& \\
Subscripts \\
0 & initial \\
$\mathrm{S}$ & solid \\
$\mathrm{L}$ & liquid \\
\end{tabular}

ucts and conditions of drying. The fundamental models are based on the mass conservation equations in each phase and can be differentiated by their assumptions and mathematical expressions. Vacarezza (1975) presented a model based on two assumptions: the shrinkage is ideal and the material is composed of two phases (solid phase and liquid phase). Suzuki et al. (1976) worked out three models of drying based on the absence of porosity in foodstuffs (model of uniform drying, drying with wet core and drying with semi wet core). Lozano et al. (1983) worked out a linear correlation for fruits and vegetables according to the mass fractions of starch, glucose and cell membranes. Perez and Calvelo (1984) carried out a model of meat shrinkage. They neglected the presence of the gas phase at the beginning of the thermal process and considered its formation during drying. Mulet et al. (2000) studied the influence of the sample shape on the shrinkage of potato. Madamba et al. (1994) and Wang and Brennan (1995) studied the variation of the physical properties (shrinkage, porosity and density) of fruit and vegetables. Rahman et al. (1996) carried out a shrinkage model which was validated for squid by taking into account the presence of three phases (solid, liquid and gas) during drying. Mayor and Sereno (2004) modified the model proposed by Perez and Calvelo (1984) by introduction of initial porosity parameter.

In the present work, the model of shrinkage by Katekawa and Silva (2004) is used using the methodology developed by Madiouli et al. (2007). The model involves a limited number of material properties (initial bulk density, solid true density and liquid true density), measured at the beginning and at the end of a drying experiment, and the simultaneous acquisition of the reduced moisture content and the volume shrinkage during drying. From a literature review, various drying processes involving different shrinkage behaviours and porosity developments in different foodstuffs are examined. A straightforward expression of the porosity change vs. moisture content is proposed and applied to this set of literature data with a special focus on error estimation.

\section{Presentation of the model}

Based on the mass conservation and the volume additivity of the various sample phases, the change of the apparent volume as a function of moisture content is given by the following equation (Katekawa and Silva, 2004; Madiouli et al., 2007):

$\mathrm{z}=\left.\frac{\mathrm{V}}{\mathrm{V}_{0}}\right|_{\exp }=\frac{1-\varepsilon_{0}}{1-\varepsilon}\left(\mathrm{A}(\beta) \frac{\mathrm{X}}{\mathrm{X}_{0}}+\mathrm{B}(\beta)\right)$

where

$\mathrm{A}(\beta)=\frac{\mathrm{X}_{0} \beta}{1+\beta \mathrm{X}_{0}}$

$\mathrm{B}(\beta)=\frac{1}{1+\beta \mathrm{X}_{0}}$

$\beta=\frac{\rho_{\mathrm{S}}}{\rho_{\mathrm{L}}}$

where the initial porosity can be derived from a set of parameters:

$\varepsilon_{0}=1-\frac{\rho_{0}}{\rho_{\mathrm{S}}} \frac{1+\beta \mathrm{X}_{0}}{1+\mathrm{X}_{0}}$

The ideal shrinkage depends on the solid density, liquid density, initial density and moisture content. It can be derived from Eq. (1) and assuming $\varepsilon=0$ and $\varepsilon_{0}=0$ (Vacarezza, 1975):

$y=\left.\frac{\mathrm{V}}{\mathrm{V}_{0}}\right|_{\text {ideal }}=\frac{\rho_{0}}{1+\mathrm{X}_{0}}\left(\frac{1}{\rho_{\mathrm{S}}}+\frac{\mathrm{X}}{\rho_{\mathrm{L}}}\right)$

Zogzas et al. (1994) formulated a math model which enabled to compute the porosity by assuming the absence of the gas phase at initial state. Rahman (2003) assumed the presence of the initial porosity and function of the shrinkage-expansion coefficient allowing to determine the fraction of the water volume removed during drying and replaced by air. Khalloufi et al. (2009) presented their porosity model function of moisture content by studying the effect of the air initial volume change when drying in extreme conditions.

In this paper, the porosity can be calculated from Eq. (1) and written in the following form:

$\varepsilon=1-\left[\frac{\left(1-\varepsilon_{0}\right)\left(\mathrm{A}(\beta)\left(\mathrm{X} / \mathrm{X}_{0}\right)+\mathrm{B}(\beta)\right)}{\left(\mathrm{V} / \mathrm{V}_{0}\right)}\right]$

In another way and according to the work of Madiouli et al. (2007), the porosity can be deduced from the shrinkage curve vs. the reduced moisture content. It can be easily shown that the porosity can be deduced from a combination of the experimental $V / V_{0}$ value $z$ and the ideal shrinkage $y$ through the equation:

$\varepsilon=\frac{z-\left(1-\varepsilon_{0}\right) y}{z}$

The previous equation has also a graphical interpretation on the shrinkage diagram. A new baseline (ideal shrinkage biased curve) is deduced from the ideal shrinkage curve by multiplying it by the quantity $\left(1-\varepsilon_{0}\right)$. The porosity is deduced using this baseline.

The calculation of the porosity thus depends on the experimental values of the shrinkage and a set of properties (initial moisture content, solid density, initial bulk density and liquid density). The error of the porosity calculation is then derived from the experimental errors made during the determination of the shrinkage curves and the errors on the properties used in the model. 


\subsection{Error calculations for the case of ideal shrinkage}

The differentiation of Eq. (6) yields:

$$
\begin{aligned}
\frac{\Delta\left(\mathrm{V} / \mathrm{V}_{0}\right)}{\left(\mathrm{V} / \mathrm{V}_{0}\right)}= & \frac{\Delta \rho_{0}}{\rho_{0}}+\frac{\Delta \mathrm{X}_{0}}{\mathrm{X}_{0}+1}+\frac{1}{\rho_{\mathrm{S}}(1+\beta \mathrm{X})} \Delta \rho_{\mathrm{S}}+\frac{1}{(1 / \beta)+\mathrm{X}} \Delta \mathrm{X} \\
& +\frac{\mathrm{X}}{\rho_{\mathrm{L}}((1 / \beta)+\mathrm{X})} \Delta \rho_{\mathrm{L}}
\end{aligned}
$$

The calculation of the error of the volume change in the case of ideal shrinkage needs the determination of the errors on moisture content, solid density, liquid density and initial bulk density.

\subsubsection{Experimental error of the moisture content}

The error of the moisture content follows from:

- the error of the measurement of the mass of the solid phase;

- the error of the measurement of the mass of the sample during drying.

The experimental error of the moisture content can be written as:

$\Delta X=(1+X)\left[\frac{\Delta m}{m}+\frac{\Delta m_{s}}{m_{s}}\right.$

2.1.2. Experimental error of the solid density, the liquid density and the initial bulk density

The experimental error of the solid density, the liquid density and the bulk initial density depend on measurement errors of the masses and volumes. Indeed, the solid density, the liquid density and the initial bulk density are written respectively:

$\rho_{\mathrm{S}}=\frac{m_{\mathrm{s}}}{\mathrm{V}_{\mathrm{S}}}$

$\rho_{\mathrm{L}}=\frac{m_{0}-m_{\mathrm{s}}}{\mathrm{V}_{\mathrm{p} 0}-\mathrm{V}_{\mathrm{s}}}$

$\rho_{0}=\frac{m_{0}}{V_{0}}$

The differentiation of Eqs. (11)-(13) respectively gives the errors on the solid density, the liquid density and the initial bulk density in the following form:

$$
\begin{aligned}
& \Delta \rho_{\mathrm{S}}=\rho_{\mathrm{S}}\left(\frac{\Delta m_{\mathrm{s}}}{m_{\mathrm{s}}}+\frac{\Delta \mathrm{V}_{\mathrm{s}}}{\mathrm{V}_{\mathrm{s}}}\right) \\
& \Delta \rho_{\mathrm{L}}=2 \rho_{\mathrm{L}} \quad \frac{\Delta m}{m_{0}-m_{\mathrm{s}}}+\frac{\Delta \mathrm{V}_{\mathrm{p}}}{\mathrm{V}_{\mathrm{p} 0}-\mathrm{V}_{\mathrm{s}}} \\
& \Delta \rho_{0}=\frac{\Delta m}{m_{0}}+\frac{\Delta \mathrm{V}_{0}}{\mathrm{~V}_{0}}
\end{aligned}
$$

\subsection{Error of the experimental shrinkage}

The error of the determination of the experimental shrinkage results from the error of the initial volume and bulk volume during drying. It is given by the following equation:

$$
\Delta\left(\frac{\mathrm{V}}{\mathrm{V}_{0}}\right)=\left(\frac{\mathrm{V}}{\mathrm{V}_{0}}\right)\left[\frac{\Delta \mathrm{V}_{0}}{\mathrm{~V}_{0}}+\frac{\Delta \mathrm{V}}{\mathrm{V}}\right.
$$

\subsection{Error of the calculated porosity}

The model of shrinkage elaborated by Katekawa and Silva (2004) may be written in the following form:

$(1-\varepsilon) \frac{\mathrm{V}}{\mathrm{V}_{0}}=\frac{\rho_{0}}{\mathrm{X}_{0}+1}\left[\frac{1}{\rho_{\mathrm{S}}}+\frac{1}{\rho_{\mathrm{L}}} \mathrm{X}\right.$

This equation allows to write the expression of the porosity:

$\varepsilon=1-\left[\frac{\left(\rho_{0} /\left(\mathrm{X}_{0}+1\right)\right)\left(\left(1 / \rho_{\mathrm{S}}\right)+\left(1 / \rho_{\mathrm{L}}\right) \mathrm{X}\right)}{\mathrm{V} / \mathrm{V}_{0}}\right]$

The error of the calculated porosity (Madiouli et al., 2007), depends on the experimental errors on many parameters. The differentiation of Eq. (18) yields:

$$
\begin{aligned}
\frac{\Delta \varepsilon}{1-\varepsilon}= & \frac{\Delta \mathrm{V}}{\mathrm{V}}+\frac{\Delta \mathrm{V}_{0}}{\mathrm{~V}_{0}}+\frac{\Delta \rho_{0}}{\rho_{0}}+\frac{\Delta \mathrm{X}_{0}}{\mathrm{X}_{0}+1}+\frac{\Delta \rho_{\mathrm{S}}}{\rho_{\mathrm{S}}(1+\beta \mathrm{X})}+\frac{\beta \Delta \mathrm{X}}{1+\beta \mathrm{X}} \\
& +\frac{(\beta \mathrm{X}) \Delta \rho_{\mathrm{L}}}{\rho_{\mathrm{L}}(1+\beta \mathrm{X})}
\end{aligned}
$$

\section{Application of the model for various foodstuffs under various drying modes}

In order to calculate porosities, we applied the shrinkage model for various foodstuffs (apple, banana, carrot, potato, sweet potato, garlic and pear) dried under various modes (convective drying and freeze drying). The data were collected from different authors (Table 1). For these foodstuffs, three properties were listed: the bulk initial density, the liquid density and the solid density - with the experimental methods used to obtain these data (Table 2).

\section{Results and discussion}

Using Eqs. (10), (14)-(17) and (20), the errors on the initial bulk density, solid density, liquid density, initial moisture content, and initial calculated porosity of some foodstuffs were calculated (Table 2).

\subsection{Convective drying}

In the case of convective drying, the seven tested products were classified in various classes according to the shrinkage and porosity changing during drying. The experimental works of Lozano et al. (1983), Lozano et al. (1980), Zogzas et al. (1994), Krokida and Maroulis (1997) and Katekawa and Silva (2004) were used for the application of the model for apple, carrot, potato, sweet potato, garlic and pear in order to calculate porosity changes during drying.

\subsubsection{Ideal shrinkage (carrot and potato)}

The shrinkage of carrot is reported to be ideal for convective drying (Zogzas et al., 1994; Krokida and Maroulis, 1997). Fig. 1 shows the experimental data from Zogzas et al. (1994). With the experimental values of $\rho_{\mathrm{S}}, \rho_{0}$ and $\rho_{\mathrm{L}}$, given by the authors (Table 1), an initial porosity of $0.4 \%$ was calculated (Table 2). Eq. (19) allowed to determine porosity during the whole drying process. Except for small values of the moisture content $\left(\mathrm{X} / \mathrm{X}_{0} \leq 0.1\right)$, comparison with the experimental porosity clearly shows an excellent agreement and porosity may be neglected, thus confirming ideal shrinkage. The 


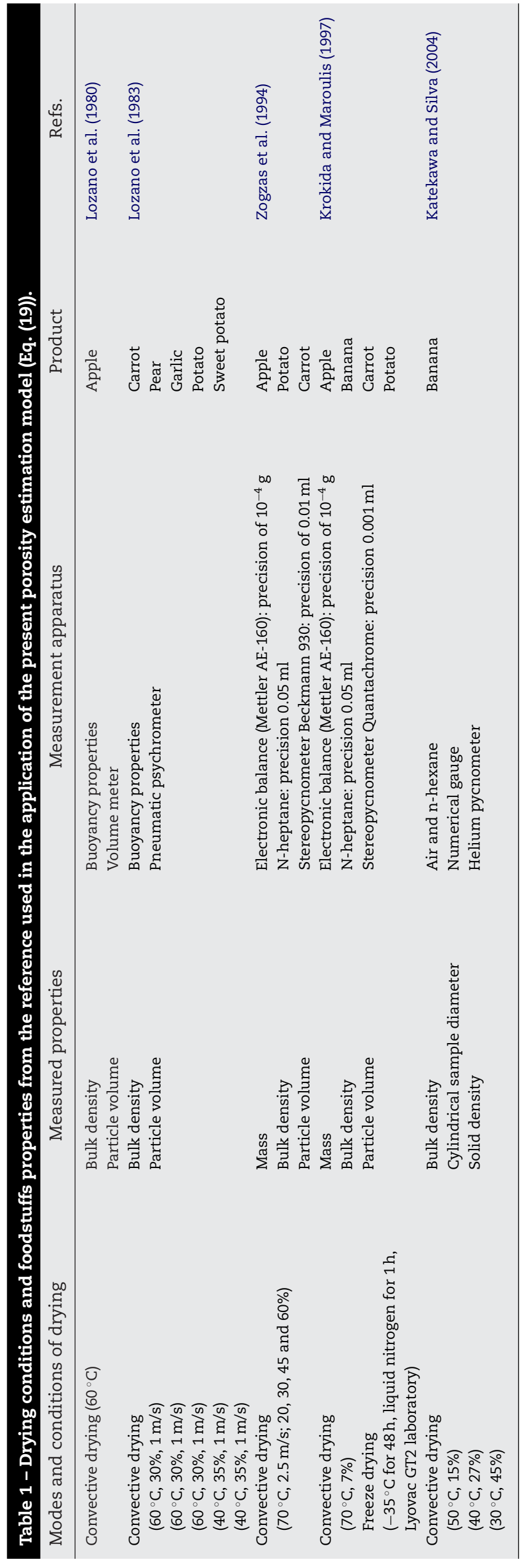

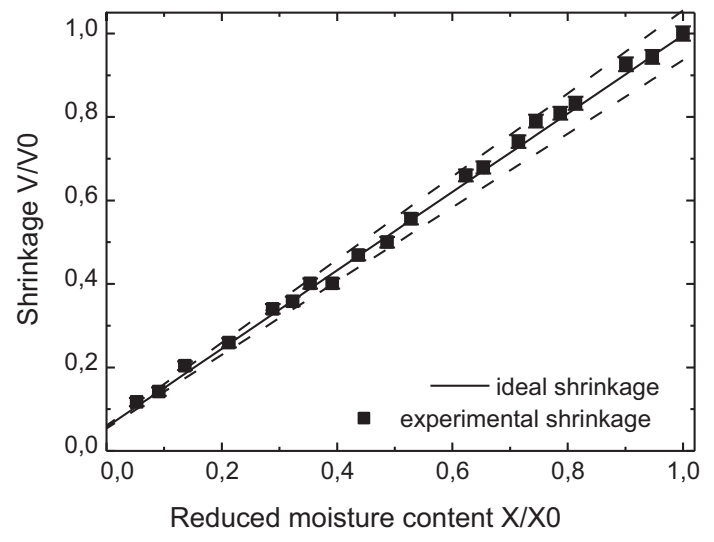

Fig. 1 - Experimental and ideal shrinkage of carrot as a function of the water content: convective drying (Zogzas et al., 1994); ideal shrinkage with error of measurement (dashes).

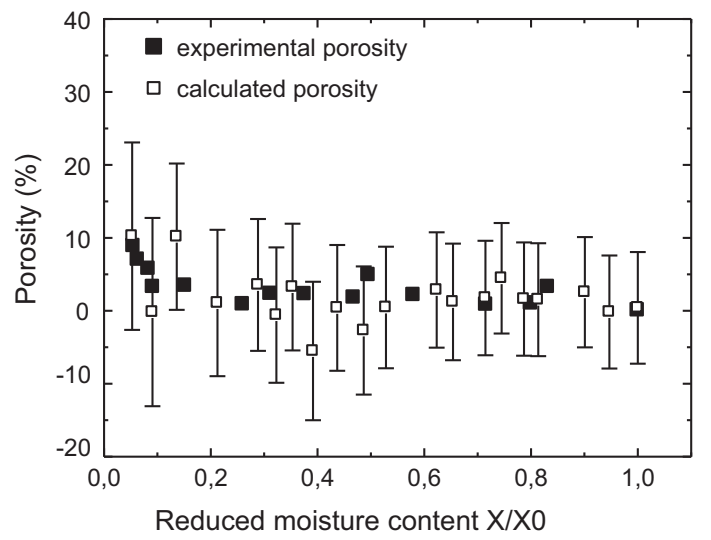

Fig. 2 - Experimental and calculated porosity of carrot as a function of the water content: convective drying (Zogzas et al., 1994).

dashed lines on Fig. 1 show the upper and lower positions of the shrinkage curve when the three properties $\rho_{\mathrm{S}}, \rho_{0}$ and $\rho_{\mathrm{L}}$ vary according to the error calculations. The negative values of calculated porosity cannot be accepted for obvious reasons (Fig. 2). For the experimental works by Krokida and Maroulis (1997) shown in Fig. 3, experimental values show an important initial porosity (13\%) whereas porosity calculations are in conformity with those performed with Zogzas

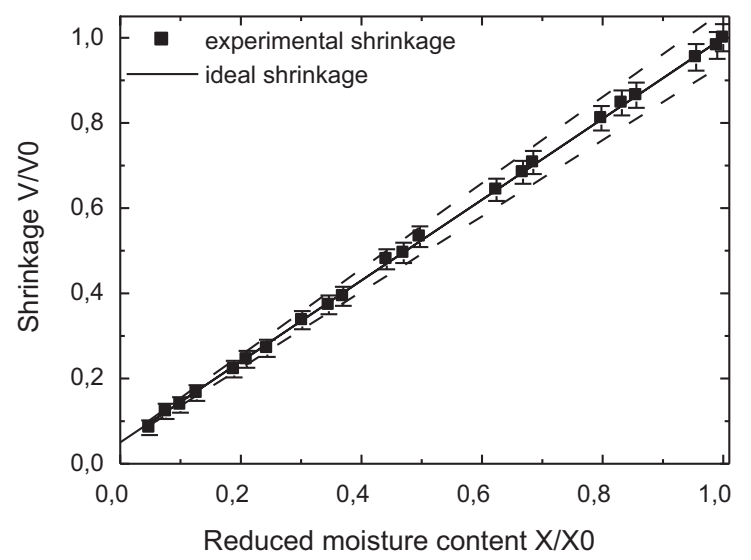

Fig. 3 - Experimental and ideal shrinkage of carrot as a function of the water content: convective drying (Krokida and Maroulis, 1997); ideal shrinkage with error of measurement (dashes). 
Table 2 - Properties of the studied foodstuffs with errors and experimental methods to obtain these properties for the references used in the application of the present model.

\begin{tabular}{|c|c|c|c|c|c|}
\hline Product & $\begin{array}{l}\text { Initial bulk } \\
\text { density }\left(\mathrm{kg} / \mathrm{m}^{3}\right)\end{array}$ & $\begin{array}{l}\text { Solid density } \\
\left(\mathrm{kg} / \mathrm{m}^{3}\right)\end{array}$ & $\begin{array}{l}\text { Liquid density } \\
\left(\mathrm{kg} / \mathrm{m}^{3}\right)\end{array}$ & $\begin{array}{l}\text { Initial } \\
\text { moisture } \\
\text { content }(\mathrm{kg} / \mathrm{kg})\end{array}$ & $\begin{array}{l}\text { Initial } \\
\text { calculated } \\
\text { porosity (\%) }\end{array}$ \\
\hline \multicolumn{6}{|c|}{ Lozano et al. (1980): convective drying } \\
\hline Apple & $853.5(1.1)$ & $1540(1.2)$ & 1000 & 7.45 & 18.2 \\
\hline \multicolumn{6}{|c|}{ Lozano et al. (1983): convective drying } \\
\hline Carrot & $1026(1.1)$ & $1530(2)$ & 1000 & 7.55 & 1.6 \\
\hline Garlic & $980(1.1)$ & $1383(2)$ & 1000 & 2.28 & 10.3 \\
\hline Pear & $993(1.1)$ & $1473(2)$ & 1000 & 7.03 & 4.7 \\
\hline Potato & $1050(1.1)$ & $1316(2)$ & 1000 & 4.5 & -0.4 \\
\hline Sweet potato & $1038(1.1)$ & $1559(2)$ & 1000 & 2.55 & 6.7 \\
\hline \multicolumn{6}{|c|}{ Zogzas et al. (1994): convective drying } \\
\hline Apple & $888 \pm 7.6(3.1)$ & $1510 \pm 37(3.2)$ & $1040 \pm 4.78$ & $7.4 \pm 0.001$ & $18.2 \pm 3.69$ \\
\hline Carrot & $1056 \pm 9.0(3.1)$ & $1610 \pm 45.82(3.2)$ & $1020 \pm 3.85$ & $9.82 \pm 0.002$ & $0.4 \pm 5.35$ \\
\hline Potato & $1041 \pm 8.9(3.1)$ & $1500 \pm 39.95(3.2)$ & $1020 \pm 3.73$ & $9.71 \pm 0.002$ & $1 \pm 5.31$ \\
\hline \multicolumn{6}{|c|}{ Krokida and Maroulis (1997): convective drying } \\
\hline Apple & $927.2 \pm 14.7(3.1)$ & $1650 \pm 10.6(4)$ & $1000 \pm 0.82$ & $9.27 \pm 0.04$ & $9.4 \pm 8.17$ \\
\hline Banana & $1053.9 \pm 16.8(3.1)$ & $1920 \pm 7.3(4)$ & $1000 \pm 0.82$ & $4.93 \pm 0.001$ & $3.4 \pm 5.46$ \\
\hline Potato & $1046.2 \pm 16.8(3.1)$ & $1610 \pm 6.6(4)$ & $1000 \pm 0.77$ & $7.01 \pm 0.002$ & $3.1 \pm 6.47$ \\
\hline Carrot & $1059 \pm 16.8(3.1)$ & $1770 \pm 10.4(4)$ & $1000 \pm 0.75$ & $9.69 \pm 0.003$ & $0 \pm 8.94$ \\
\hline \multicolumn{6}{|c|}{ Krokida and Maroulis (1997): freeze drying } \\
\hline Apple & $927.2 \pm 18.4(3.1)$ & $1650 \pm 12.7(4)$ & $1000 \pm 1.02$ & $9.27 \pm 0.001$ & $11.31 \pm 10$ \\
\hline Banana & $1053.9 \pm 21.0(3.1)$ & $1920 \pm 9.1(4)$ & $1000 \pm 1.02$ & $4.93 \pm 0.001$ & $3.4 \pm 6.82$ \\
\hline Potato & $1046.2 \pm 21(3.1)$ & $1610 \pm 9.1(4)$ & $1000 \pm 0.97$ & $7.01 \pm 0.001$ & $0.5 \pm 7$ \\
\hline Carrot & $1059 \pm 21.0(3.1)$ & $1770 \pm 9.1(4)$ & $1000 \pm 0.98$ & $9.69 \pm 0.001$ & $1.6 \pm 7.15$ \\
\hline \multicolumn{6}{|c|}{ Katekawa and Silva (2004): convective drying } \\
\hline Banana at $30^{\circ} \mathrm{C}$ and $\mathrm{RH}=45 \%$ & $1025(5.1)$ & $1497(5.2)$ & 1000 & 3.15 & 5.7 \\
\hline Banana at $40^{\circ} \mathrm{C}$ and $\mathrm{RH}=27 \%$ & $1025(5.1)$ & $1497(5.2)$ & 1000 & 2.85 & 6.3 \\
\hline Banana at $50^{\circ} \mathrm{C}$ and $\mathrm{RH}=15 \%$ & $1025(5.1)$ & $1497(5.2)$ & 1000 & 2.5 & 7.2 \\
\hline
\end{tabular}

1.1, buoyancy properties; 1.2, volume meter; 2, pneumatic psychrometer; 3.1, n-heptane; 3.2, Stereopycnometer Beckmann 930; 4, Stereopycnometer Quantachrome; 5.1, n-hexane; 5.2, helium pycnometer.

experimental results (Fig. 4). This discrepancy rather suggests that experimental procedures for porosity measurement should be carefully checked. Another discrepancy is observed: there is little coherence between ideal shrinkage behaviour for low moisture content as seen on Figs. 1 and 3 and the porosity increase observed experimentally. This discrepancy cannot only be attributed to porosimetry measurements. One possible explanation is that constraint's relaxations may introduce porosity after manipulation of samples for stereopycnometry. However, the accuracy of calculations at low moisture content may be questioned.

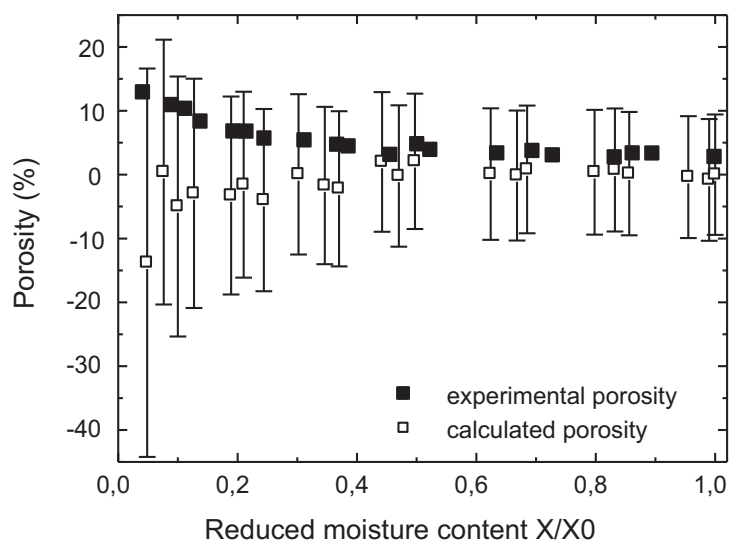

Fig. 4 - Experimental and calculated porosity of carrot as a function of the water content: convective drying (Krokida and Maroulis, 1997).
Potato behaves the same way as carrot in the case of the convective drying experiments carried out by Zogzas et al. (1994) (Fig. 5). The experimental measurements of porosity during drying also show negligible porosity development. However calculations show an important porosity development for $\mathrm{X} / \mathrm{X}_{0} \leq 0.3$ (Fig. 6.). For low moisture values, calculations are very sensitive to the $y$-intercept of the shrinkage curve, whose value is $y(X=0)=\rho_{0} /\left(\rho_{s}\left(1+X_{0}\right)\right)$. A possible explanation for this discrepancy would be a modification of the amylaceous solid phase density due to heat effects.

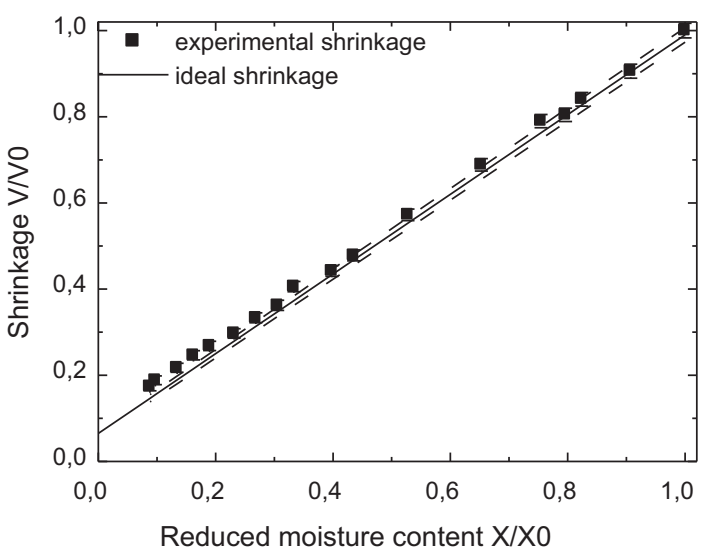

Fig. 5 - Experimental and ideal shrinkage of potato as a function of the water content: convective drying (Zogzas et al., 1994); ideal shrinkage with error of measurement (dashes). 


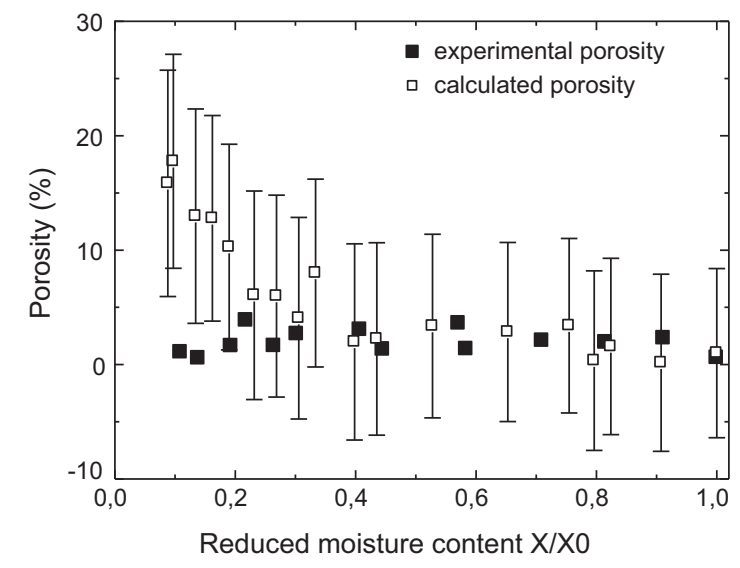

Fig. 6 - Experimental and calculated porosity of potato as a function of the water content: convective drying (Zogzas et al., 1994).

Other experiments by Lozano et al. (1983) and Krokida and Maroulis (1997), showed that potato may be classified with the other foodstuffs described thereafter for the non-ideal case, which seems to show that specific phenomena may occur in the drying of potatoes.

\subsubsection{Non ideal shrinkage (sweet potato, garlic, pear and banana)}

Sweet potato, garlic and pear are characterized by the same shrinkage behaviour (Lozano et al., 1983). They exhibit a linear shrinkage with a smaller slope than for ideal shrinkage down to a critical value of the reduced moisture content $X / X_{0}$. The experimental porosity of these foodstuffs is small and it remains either constant (sweet potato, potato and garlic) or it decreases slightly (pear). The decrease of porosity in the first stages of drying was interpreted as a collapse of the solid matrix and modelled by Khalloufi et al. $(2009,2010)$. Although the calculated porosity of pear fits quite well with the experimental results, this decrease was not observed. The calculated porosity remains almost constant around $5 \%$ before a sharp increase at low moisture content. For sweet potato (Fig. 7) and garlic (Fig. 8), the fitting is not correct. The experimental porosity is much higher than the calculated one. No straightforward interpretation of this discrepancy can be given.

For banana, the shrinkage curve has the same form as for sweet potato, garlic and pear (Fig. 10). Fig. 11 shows the porosity change as a function of the reduced moisture content

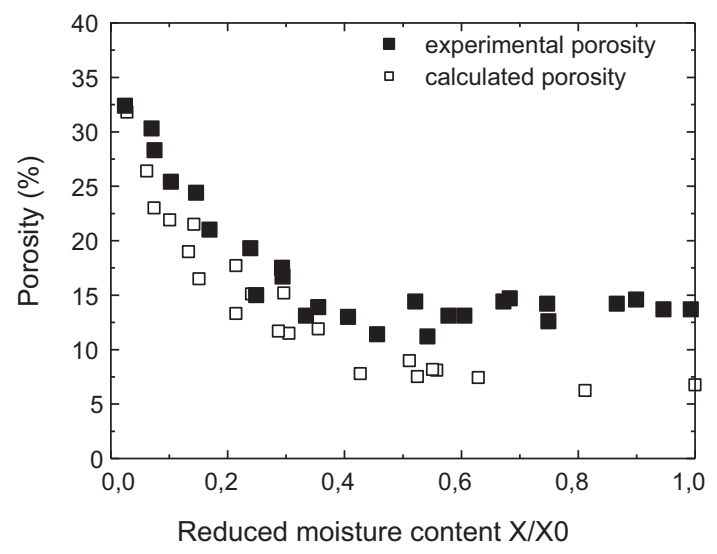

Fig. 7 - Experimental and calculated porosity of sweet potato as a function of the water content: convective drying (Lozano et al., 1983).

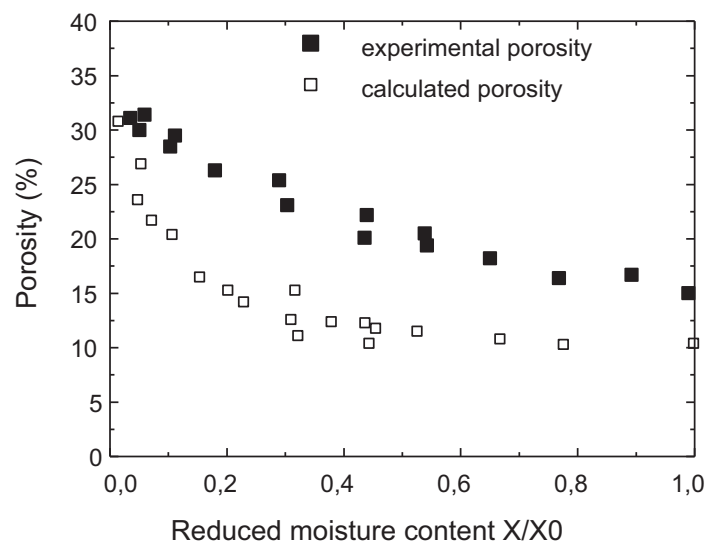

Fig. 8 - Experimental and calculated porosity of garlic as a function of the water content: convective drying (Lozano et al., 1983).

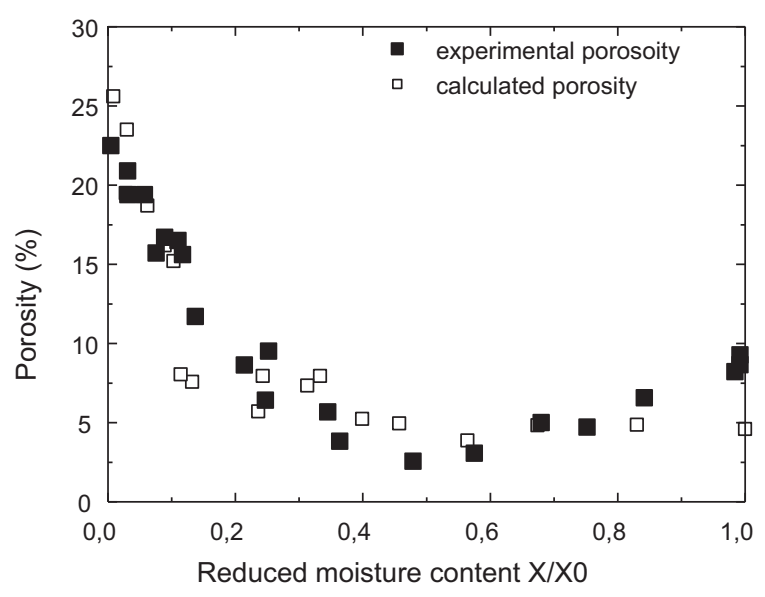

Fig. 9 - Experimental and calculated porosity of pear as a function of the water content: convective drying (Lozano et al., 1983).

using the data from Krokida and Maroulis (1997). For the major part of the drying process, porosity remains practically constant, but, when the value of $\mathrm{X} / \mathrm{X}_{0}$ is smaller than 0.3 , porosity increases. As for potato, this increase is hardly observed using the porosity model, which may be interpreted as a specific behaviour of amylaceous foodstuffs. The porosity of samples during drying seems to depend on the drying temperature,

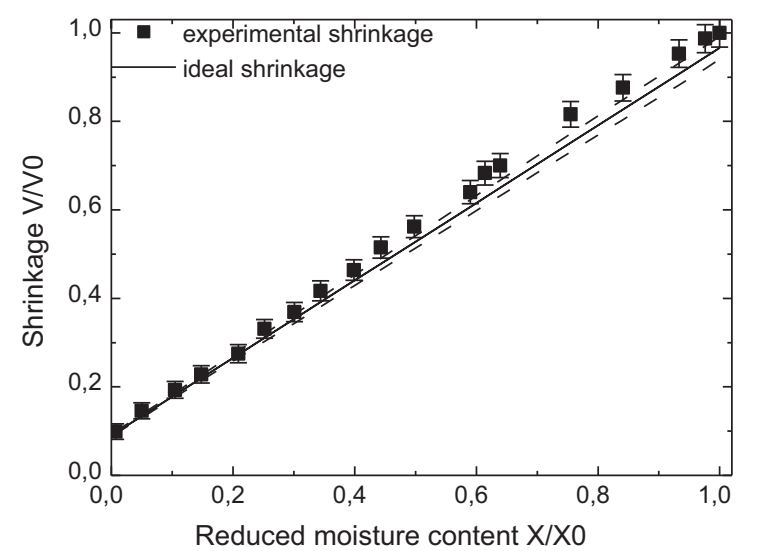

Fig. 10 - Experimental and ideal shrinkage of banana as a function of the water content: convective drying (Krokida and Maroulis, 1997); ideal shrinkage with error of measurement (dashes). 


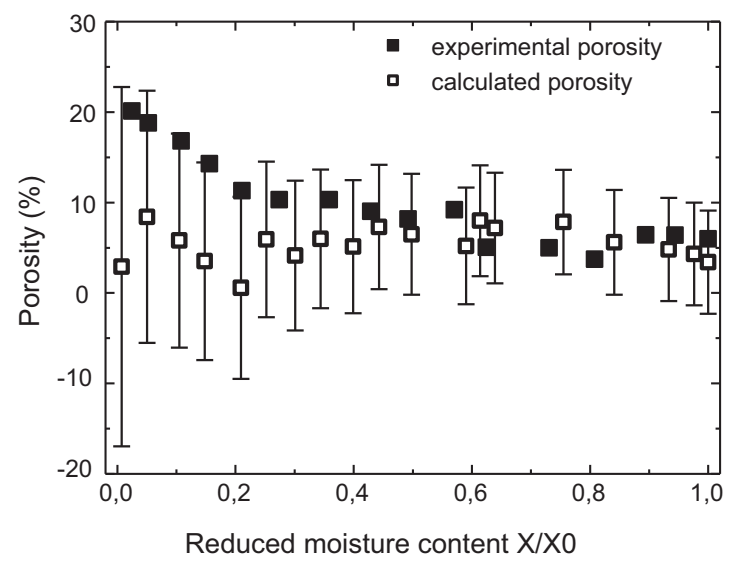

Fig. 11 - Experimental and calculated porosity of banana as a function of the water content: convective drying (Krokida and Maroulis, 1997).

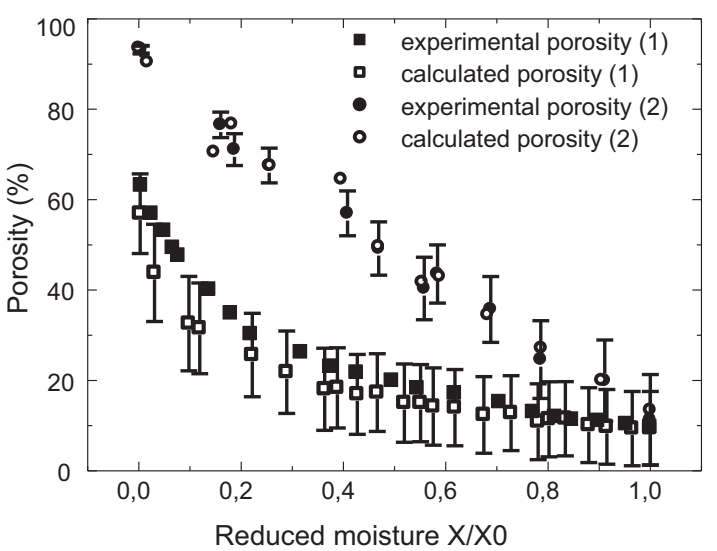

Fig. 12 - Experimental and calculated porosity of apple as a function of the water content (Krokida and Maroulis, 1997): (1) convective drying and (2) freeze drying.

since the largest porosity is developed in the case of the experiments by Krokida and Maroulis who applied the highest air temperature for convective drying $\left(70^{\circ} \mathrm{C}\right)$.

\subsubsection{Non-ideal shrinkage (apple)}

The experimental results for apple were obtained by Zogzas et al. (1994) and Krokida and Maroulis (1997). The shrinkage of apple is linear with a lower slope than the ideal shrinkage

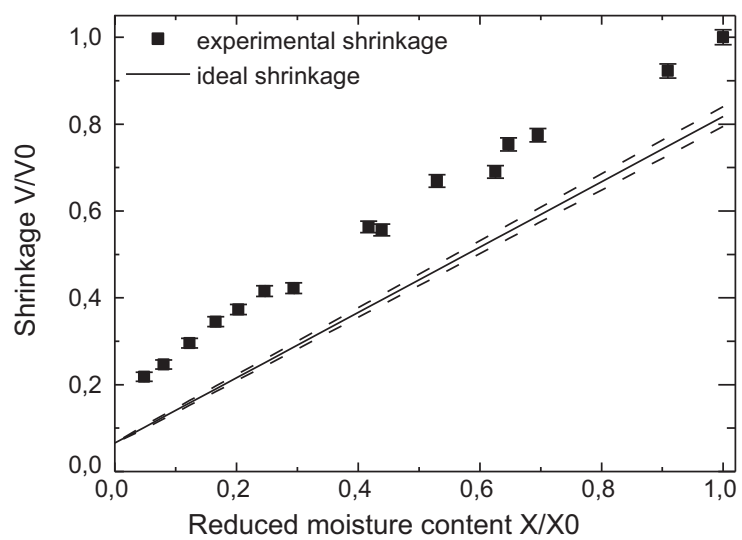

Fig. 13 - Experimental and ideal shrinkage of apple as a function of the water content: convective drying (Zogzas et al., 1994); ideal shrinkage with error of measurement (dashes).

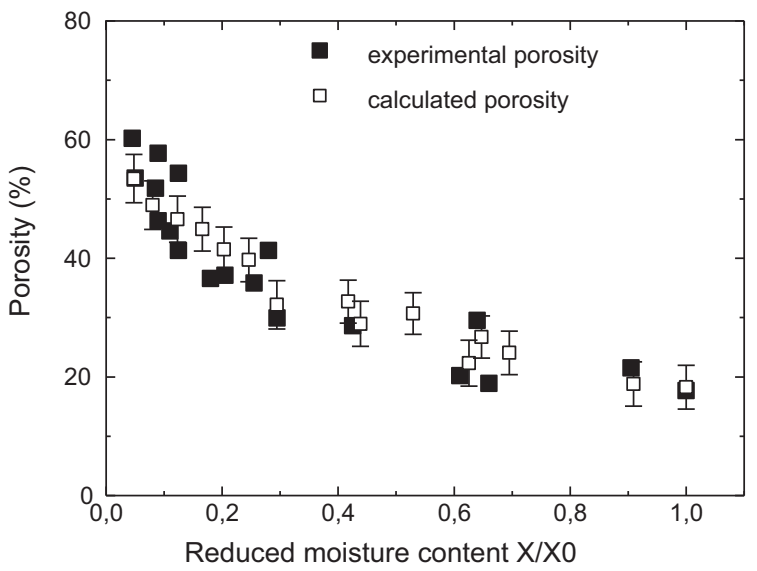

Fig. 14 - Experimental and calculated porosity of apple as a function of the water content: convective drying (Zogzas et al., 1994).

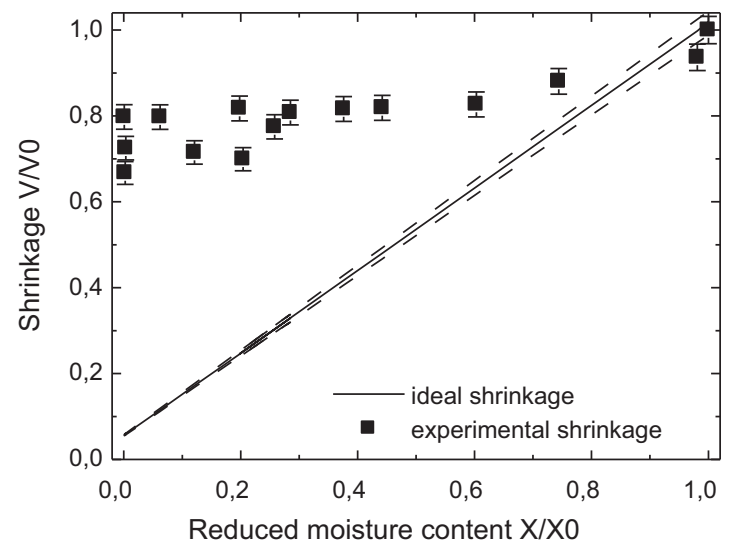

Fig. 15 - Experimental and ideal shrinkage of carrot as a function of the water content: freeze drying (Krokida and Maroulis, 1997).

(Fig. 13). This linear behaviour of the experimental shrinkage results in the increase of porosity, starting from its relatively high initial value (18\%) to reach an end value of $60 \%$ (Figs. 12 (plot 1) and 14). In comparison with the other foodstuffs, apple is characterized by a high porosity during drying. The results present a small deviation compared to experimental porosity. This deviation can be due to the errors of experimental measurement of the initial bulk density and the

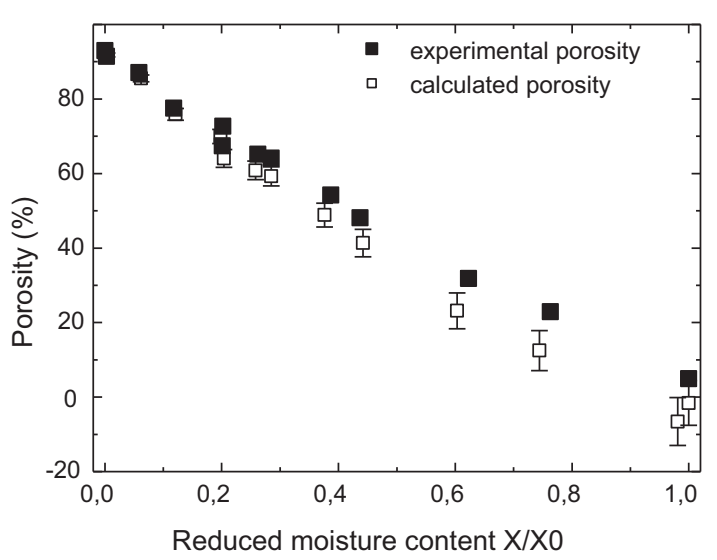

Fig. 16 - Experimental and calculated porosity of carrot as a function of the water content: freeze drying (Krokida and Maroulis, 1997). 


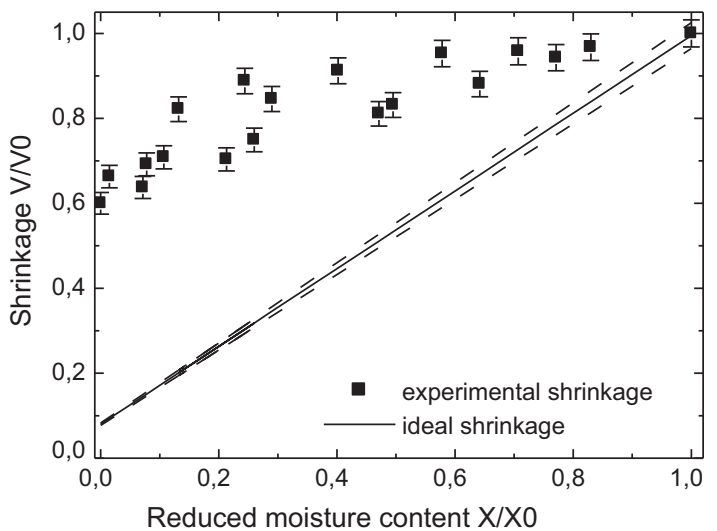

Fig. 17 - Experimental and ideal shrinkage of potato as a function of the water content: freeze drying (Krokida and Maroulis, 1997); ideal shrinkage with error of measurement (dashes).

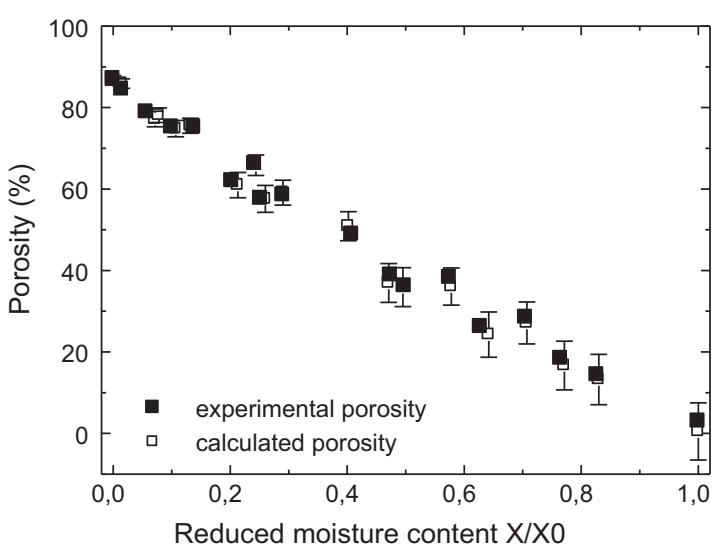

Fig. 18 - Experimental and calculated porosity of potato as a function of the water content: freeze drying (Krokida and Maroulis, 1997).

non-homogeneity of the samples. Fig. 13 clearly shows that the ratio between the volume of air and the initial volume remains almost constant above $\mathrm{X} / \mathrm{X}_{0}=0.4$.

\subsection{Freeze-drying}

In the case of freeze-drying, the foodstuffs have rather a high porosity at the end of drying. This phenomenon follows

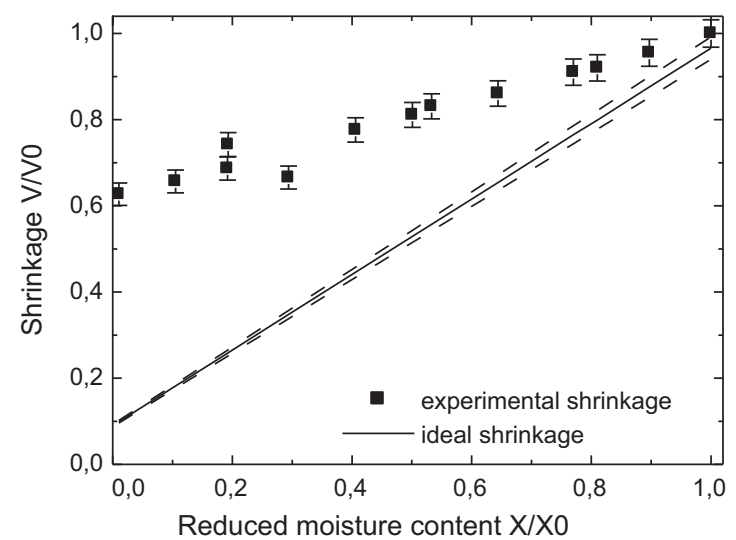

Fig. 19 - Experimental and ideal shrinkage of banana as a function of the water content: freeze drying (Krokida and Maroulis, 1997); ideal shrinkage with error of measurement (dashes).

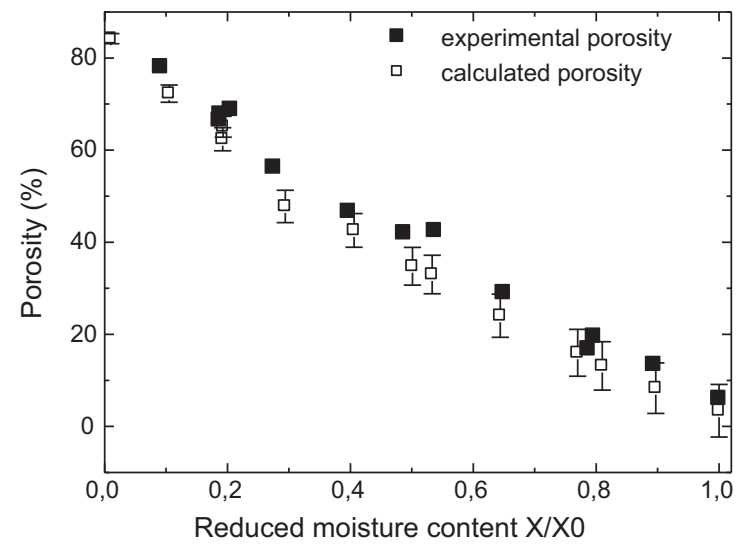

Fig. 20 - Experimental and calculated porosity of banana as a function of the water content: freeze drying (Krokida and Maroulis, 1997).

from the absence of capillary forces during sublimation of the frozen solvent. The final porosity of the foodstuff reaches $90 \%$ for apple and it remains between 80 and $85 \%$ in case of carrot, potato and banana. By applying the shrinkage model for apple, potato, carrot and banana in the case of freeze-drying (the temperature is $-35^{\circ} \mathrm{C}$ and the pressure is $0.04 \mathrm{mbar}$ ), the experimental shrinkage of these products is linear with a smaller slope than that of the curves of the ideal shrinkage (Figs. 15, 17 and 19). The porosity calculated by the model is close to experimental porosity and it varies linearly, which suggests the conservation of a porous skeleton of various foodstuffs during drying (Figs. 12, 16, 18 and 20). The error of the calculated porosity does not exceed $5 \%$ for all the experiments.

\section{Conclusion}

With the mere knowledge of the following parameters: solid density, liquid density and initial bulk density and the follow up of the quantities $\mathrm{X} / \mathrm{X}_{0}$ (reduced moisture content) and $\mathrm{V} / \mathrm{V}_{0}$ (volume shrinkage), the proposed method allowed to calculate the bulk porosity (including closed and opened pores) whereas the direct experimental methods may be unable to account for crack formations or closed porosities. We have validated this model by applying it to experimental data from the literature, carried out under various drying modes (convective drying and freeze drying). For two of the studied materials (carrot, potato), the initial porosity was negligible. For the others (apple, banana, sweet potato, garlic and pear), the initial porosity was relevant. Except for garlic and partly for sweet potato, a good agreement between the calculated and the experimental porosity. When the experimental porosity was obtained by stereopycnometry, the agreement with calculated porosities was good, which suggests that the samples treated by these measurement techniques are representative of the bulk behaviour of the product. This was particularly the case for the experiments in convective drying by Zogzas et al. (1994) for carrot (Fig. 3) and apples (Fig. 14) and by Lozano et al. (1983) for pears (Fig. 9) as well as for all the experiments conducted in freeze drying for carrot, potato and banana (Krokida and Maroulis, 1997). In many cases, differences between experimental and theoretical porosities are observed at the initial stage of drying. These differences can be attributed to the sampling protocol and experimental device rather than to the heterogeneity in the solid. Differences observed at low moisture contents may be attributed to crack formation or chemical 
reactions occurring in the solid phase at the drying temperature, although errors also become very meaningful and may affect the accuracy of the calculations.

Because the present method is based on simple and accurate methods (mass and length measurements) and relies on complementary density measurements, because it does not require to stop experiments and cut samples in the foodstuffs, it is a powerful tool to obtain information on the porosity change of a drying foodstuff under various external conditions. It should be completed by more local measurement techniques in order to attribute porosity change to physical (collapse, expansion, cracks formation) or chemical phenomena (crystallization, glass transition, reactions in solid or liquid phase) and observe the scale of porosity formation.

\section{References}

Azzouz, S., Guizani, A., Jomaa, W., Belgith, A., 2002. Moisture diffusivity and drying kinetic equation of convective drying of grapes. Journal of Food Engineering 55 (4), 323-330.

Azzouz, S., Jomaa, W., Belghith, A., 1998. Drying kinetic equation of single layer of grapes. In: IDS'98, Proceedings of 11th International Drying Symposium (IDS'98), vol. B , Halkidiki, Greece, August 19-22, pp. 988-997.

Katekawa, M.E., Silva, M.A., 2004. Study of porosity behavior in convective drying of bananas. In: Proceedings of the 14th International Drying Symposium (IDS 2004), vol. B , Sao-Paulo, Brazil, August 22-25, pp. 1427-1434.

Khalloufi, S., Almeida-Riviera, C., Bongers, P., 2009. A theoretical model and its experimental validation to predict the porosity as a function of shrinkage and collapse phenomena during drying. Food Research International 42, 1122-1130.

Khalloufi, S., Almeida-Riviera, C., Bongers, P., 2010. A fundamental approach and its experimental validation to simulate density as a function of moisture content during drying processes. Journal of Food Engineering 97, 177-187.

Krokida, M.K., Maroulis, Z.B., 1997. Effect of drying method on shrinkage and porosity. Drying Technology 15 (10), 2441-2458.

Lozano, J.E., Rotstein, E., Urbicain, M.J., 1983. Shrinkage, porosity and bulk density of foodstuffs at changing moisture contents. Journal of Food Science 48, 1497-1502.
Lozano, J.E., Rotstein, E., Urbicain, M.J., 1980. Total porosity and open-pore porosity in the drying of fruits. Journal of Food Science 45, 1403-1407.

Madamba, P.S., Driscoll, R.H., Buckle, K.A., 1994. Shrinkage, density and porosity of garlic during drying. Journal of Food Engineering 23, 309-319.

Madiouli, J., Lecomte, D., Nganya, T., Chavez, S., Sghaier, J., Sammouda, H., 2007. A method for determination of porosity change from shrinkage curves of deformable materials. Drying Technology 25 (4), 621-628.

Mayor, L., Sereno, A.M., 2004. Modelling shrinkage during convective drying of food material: a review. Journal of Food Engineering 61, 373-386.

Mulet, A., Garcia-Reverter, J., Bon, J., Berna, A., 2000. Effect of shape on potato and cauliflower shrinkage during drying. Drying Technology 18 (6), 1201-1219.

Perez, M.G., Calvelo, A., 1984. Modeling the thermal conductivity of cooked meat. Journal of Food Science 49, 152-156.

Rahman, M.S., 2003. A theoretical model to predict the formation of pores in foods during drying. International Journal of Food Properties 6 (1), 61-72.

Rahman, M.S., Perera, C.O., Chen, X.D., Driscoll, R.H., Potluri, P.L., 1996. Density shrinkage and porosity of calamari mantle meat during air drying in a cabinet dryer as a function of water content. Journal of Food Engineering 30, 135-145.

Ratti, C., 1994. Shrinkage during drying of foodstuffs. Journal of Food Engineering 23 (1), 91-105

Suzuki, K., Kubota, K., Hasegawa, T., Hosaka, H., 1976. Shrinkage in dehydratation of root vegetables. Journal of Food Science 41, 1189-1193.

Talla, A., Puiggali, J.R., Jomaa, W., Jannot, Y., 2004. Shrinkage and density evolution during drying of tropical fruits: application to banana. Journal of Food Engineering 64, 103-109.

Vacarezza, L., 1975. Cinetica y mecanismo de transporte de agua durante la deshidrataci_on de la remolacha azucarera. Ph.D. Thesis. Universidad de Buenos Aires.

Wang, N., Brennan, J.G., 1995. Changes in structure, density and porosity of potato during dehydratation. Journal of Food Engineering 24, 61-76.

Zogzas, N.P., Maroulis, Z.B., Marinos-Kouris, D., 1994. Densities, shrinkage and porosity of some vegetables during air drying. Drying Technology 12 (7), 1653-1666. 